\title{
MULHERES E ELITES LOCAIS NO MARANHÃO: PERFIS, TRAJETÓRIAS E CAMPANHAS
}

\section{Dayana dos Santos Delmiro Costa ${ }^{1}$}

Resumo: A pesquisa teve como objetivo analisar as formas de acesso das mulheres à política, relacionando o processo de constituições de elites locais, dinâmica de especialização política e gênero. Primeiramente reunimos informações sobre a posição social e as disposições dos agentes a partir das trajetórias individuais. Comparamos quatro casos representativos do processo de seleção e recrutamento das elites locais de três municípios do Maranhão: Caxias, Pinheiro e Lago da Pedra. Observamos como essas mulheres mobilizaram os trunfos decorrentes dos diferentes itinerários, espaços ocupados ao longo de suas trajetórias e como desenvolveram o trabalho de administração de redes de relações políticas e familiares para obter êxito nas disputas eleitorais. Numa abordagem quantitativa e qualitativa utilizamos a combinação de algumas técnicas como levantamento bibliográfico, pesquisa em arquivos, entrevista, observação participante em eventos de campanha (comícios, carreatas e visitas domiciliares).

Palavras- chave: Elites locais, Mulheres, Trajetórias, Campanhas.

Resumen: La investigación tuvo como objetivo analizar las formas de acceso de las mujeres a la política, sobre el proceso de constitución de las élites locales, la dinámica política de competencia y de género. En primer lugar, reunir información sobre la posición social y las disposiciones de los agentes de las trayectorias individuales, comparar cuatro casos representativos del proceso de selección y reclutamiento de las élites locales en tres municipios del estado de Maranhão: Caxias, Pinheiro e Lago da Pedra. Observamos cómo estas mujeres se movilizaron los activos resultantes de las diferentes vías, los espacios a lo largo de sus trayectorias y la forma en que ha desarrollado el trabajo administrativo de las redes de relaciones y de las políticas de familia para tener éxito en las disputas electorales. En un enfoque cuantitativo y cualitativo utiliza uma combinación de algunas de las técnicas, la investigación bibliográfica, archivística, entrevistas, observación participante em actos de campaña (mítines, caravanas y visitas a domicilio).

Palabra- clave: Élites locales; Mujeres; Trayectorias; Las campañas

Abstract: The research aimed to analyze the forms of women's access to politics, relating the process of constitution of local elites, the political dynamics of expertise and gender. First we gather information about the social position and the provisions of the agents from the individual trajectories, we compare four representative cases of the selection process and recruitment of local elites in three municipalities of Maranhão: Caxias, Pinheiro e Lago da Pedra. We observe how these women mobilized assets resulting from different routes, spaces along their trajectories and how they developed the administrative work of networks of relationships and family policies to succeed in electoral disputes. In a quantitative and qualitative approach used a combination of some techniques, bibliographic, archival research, interviews, participant observation at campaign events (rallies, motorcades and home visits).

Keyword: Local Elites, Women, Trajectories, Campaigns

\footnotetext{
${ }^{1}$ Doutoranda em Ciências Sociais no PPGCSoc- UFMA. Professora de Sociologia do Instituto Federal de Educação, Ciência e Tecnologia-IFMA. São co-autores desse artigo: Igor Gastal Grill - Professor do Programa de Pós-Graduação em Ciências Sociais-UFMA, João Gilberto do Nascimento Lima - mestrando em Ciências Sociais-UFMA e Elthon Ranyere Oliveira Aragão doutorando em Sociologia na UFS.
} 


\section{INTRODUÇÃO}

Os estudos sobre a participação das mulheres na política permitem explorar a discussão se há aspectos singulares ou não do estilo feminino de fazer política. Essa participação diferencial da mulher na política tem sido abordada por diferentes ângulos. Alguns autores privilegiam a atuação das mulheres nos mandatos, outros enfocam a especificidade em relação às campanhas eleitorais. Para Miguel (2001), apesar das múltiplas identidades femininas, fala-se de uma perspectiva social, como um ponto de partida comum, que caracteriza a contribuição diferencial da mulher na política, a exemplo da participação de forma mais recorrente em determinadas comissões ou secretarias específicas. Avelar (2001) chama atenção para o fato, de que seja qual for o seu partido, as mulheres tendem a dar mais atenção e prioridade às políticas dos direitos das mulheres e às políticas públicas relacionadas com questões familiares, tais como condições de vida para as crianças, saúde, reprodução².

Em relação às especificidades das campanhas femininas há os trabalhos de Barreira (1998, 2008). Barreira (1998) ao tomar como objeto de análise as candidaturas de mulheres nas campanhas de 1996 para prefeitura nas cidades de Fortaleza, Natal e Maceió, destacou como os discursos, slogans e rituais podem ser nomeados de jogos de identificação e diferenças. A autora demonstra como entre as candidatas há uma associação entre definição de fronteiras pelo fato de serem mulheres e, simultaneamente, colocam-se como expressão de uma totalidade reafirmando certos valores morais e políticos. Exemplifica com o acionamento de adjetivações presentes nos materiais de campanhas analisados, tais como: "mulheres de luta", "mulheres experientes" e "mulheres virtuosas" na trajetória de candidatas provenientes de diferentes contextos sociais. Demonstra, ainda, como em algumas entrevistas candidatas em busca de reconhecimento político ressaltaram qualidades que, segundo estas, estariam presentes mais nas mulheres do que em homens. As candidatas mencionam características tais como, ser mais cuidadosas, mais criativa, conseguir juntar o raciocínio com o sentimento.

Inspiramo-nos também em alguns estudos desenvolvidos na França, que relacionaram o processo de especialização política e a questão de gênero ${ }^{3}$ (Guionnet

\footnotetext{
2 Dentre os exemplos de temas defendidos por diferentes deputadas na Câmara de Deputados Federais do Brasil, relacionados com a questão feminina, destacam-se os que se relacionam com a violência doméstica; o reconhecimento da paternidade, pela aprovação da gratuidade do exame de DNA; a prevenção do câncer ginecológico gratuita; atenção para os projetos sobre mortalidade materna; licenças para mães adotantes; registros de união após 5 anos de vida em comum; direitos das empregadas domésticas, dentre outros. (Jornal C-Femea/www.cfemea.org.br)
}

\footnotetext{
3 Adotamos a perspectiva de Scott (1990) cuja contribuição serviu para se pensar a diferença sexual e a sexualidade como construções sociais que sofrem variações históricas e culturais. A autora ressalta ainda que "o gênero" é um elemento constitutivo das relações sociais, sendo estas relações significantes de poder.
} 
2002, Achin 2005, Dulong e Lévêque 2002). Todos têm em comum a influência da abordagem sócio-histórica da política de Offerlé $(1996,1999)$ no estudo das formas de acesso à política, perspectiva que adotamos no presente estudo.

Guionnet (2002) buscou identificar em que medida a variável de "gênero" foi utilizada como identidade estratégica para legitimar a inserção das mulheres na política, nas eleições municipais francesas de 2001. A autora analisou como (no contexto de "crise política”) uma variável que era historicamente rejeitada - o gênero pode ser utilizada associada à ideia de necessidade de renovação das práticas políticas 4 , como uma espécie de savoir faire feminino específico. Identificou ainda que as mulheres apesar de outsiders, devido à posição de novatas que ocupavam no campo político, às vezes precisavam relativizar a situação neófita, pois em algumas situações adquiriram uma experiência prévia que contribuía na socialização política, como militância em sindicatos, participação em associações ou envolvimento nas campanhas do marido. O que mostrou que na análise do uso do recurso de "gênero" nas disputas eleitorais é preciso considerar também a posição social dessas mulheres.

Nessa mesma linha, Dulong e Lévêque (2002) realizaram uma pesquisa sobre o uso do "gênero" como prática de mobilização eleitoral. Através de uma enquete, com homens e mulheres, com perguntas como "Quais as qualidades necessárias para se fazer uma boa campanha?", buscaram identificar se o gênero influencia nas representações sobre o métier político. Nas respostas pôde ser observado que as qualidades requisitadas para fazer campanha ou exercer um mandato municipal variam sensivelmente de acordo com o gênero, idade e experiência política dos agentes entrevistados. Os homens evocavam mais saberes técnicos enquanto que as mulheres se reportavam mais às qualidades morais e de relacionamento, como saber ouvir, compreender, conhecer a população e ser honesta.

O propósito dessa articulação entre o processo de recrutamento de "elites políticas locais" no Maranhão e a questão de gênero foi observar as lógicas sociais e políticas que agem sobre a definição das candidaturas nas eleições municipais de 2008 no Maranhão e o significado da presença feminina no cenário eleitoral. Cabe ressaltar que a presente pesquisa foi possível, por estar relacionada a um projeto ${ }^{5}$ onde a equipe de pesquisadores desenvolveu estudos que se articulam em torno de uma problemática mais ampla e que são complementares entre si.

\footnotetext{
4 (...) Là où les femmes expliquent qu'elles sont plus proches des citoyens, plus humaines et plus pragmatiques parce qu'elles s'occupent des enfantes, entretiennet les relations familiales et doivent mener une double vie de labeur (domestique et remunere), les ouvriers vantaient leurs qualités de travailleurs énergiques, honnêtes, simples, désintéressés, généreux et dévoués. (GUIONNET, 2002:125)

5 "Dinâmicas da Política Local: candidatos e eleições municipais no Maranhão", coordenado pelo professor Igor Grill do Programa de Pós-Graduação em Ciências Sociais-UFMA. A investigação contou com o auxílio do CNPq por meio do edital MCT/CNPq 02/2009 - Ciências Humanas, Sociais e Sociais Aplicadas - e com bolsas de mestrado fornecidas pela Capes e Fapema.
} 
O estudo mais amplo enfocou, em uma primeira dimensão, a extração social dos candidatos a prefeitos e as identificações partidárias dos mesmos. Em uma segunda dimensão, foram caracterizadas as disputas eleitorais em três cidades, a saber: Caxias, Pinheiro e Lago da Pedra. As análises de entrevistas em profundidade com candidatos a prefeito, apoiadores e membros da equipe de campanha, bem como de materiais impressos, jingles, observações in loco de eventos de mobilização em prol das candidaturas e inserções nos programas de TV (o chamado Horário Eleitoral Gratuito, quando era o caso), constituem as fontes de dados empíricos. A partir dos universos de disputa enfocados, é possível cotejar a dinâmica de concorrência eleitoral em municípios com características bastante discrepantes.

Foram examinadas campanhas: 1) em uma cidade em que o vencedor é alinhado com a facção que controlou o governo estadual (Caxias) até 2009 (quando Jackson Lago foi cassado) e em duas em que os prefeitos eleitos são adversários do governador eleito em 2006 e vinculados à facção liderada pela "família Sarney", que liderou a política estadual maranhense durante 40 anos (Pinheiro-MA e Lago da PedraMA); 2) em colégios eleitorais do Maranhão com tamanhos diferenciados; 3) em cenários em que as campanhas ocorrem com maior peso do espaço do horário eleitoral gratuito da TV, do marketing, dos meios de comunicação (Caxias-MA e Pinheiro-MA) ou são mais marcadas pelo "corpo-a-corpo", pelas "visitas", pelas redes de interconhecimento (com destaque para Lago da Pedra (MA), cujos candidatos a prefeito não tem acesso à aparição na TV, mas com forte influência nas demais cidades também).

Neste artigo destacamos quatro casos representativos de mulheres nas eleições municipais no Maranhão, duas candidatas a prefeita e duas candidatas a vereadora, nos referidos municípios. É interessante destacar que esses casos são pontuais. As análises dos casos não são conclusivas, estando abertas a novas questões e interpretações.

Dentre as trajetórias estudadas, percebemos algumas recorrências entre as mulheres. Primeiramente, em relação à idade de ocupação do primeiro cargo eletivo dessas mulheres, todas foram eleitas antes dos 35 anos, chamando atenção para o recrutamento precoce no processo de especialização política. Em segundo lugar, percebemos que todas tiveram uma iniciação política dentro do seio familiar, demonstrando a idéia de um trajeto peculiar na formação de político. $\mathrm{O}$ acionamento das relações de parentesco apareceu nas disputas políticas, o nome como elemento de distinção em relação aos demais candidatos envolvidos na disputa eleitoral aparece no conjunto dos casos. Em relação ao primeiro cargo eletivo, dois casos ingressam "por cima", uma como deputada federal outra como deputada estadual, e posteriormente foram prefeitas. E dois casos ingressam "por baixo", como vereadoras com votações 
expressivas. (Ver quadro abaixo).

Para uma compreensão das candidaturas em sua expressão diferenciada, faremos uma exposição das trajetórias das candidatas por município.

\section{CANDIDATURAS FEMININAS EM CAXIAS (MA)}

O município de Caxias-MA localiza-se na porção leste do estado do Maranhão, conhecida como "região dos Cocais", aproximadamente 360 km de São Luís e 60 km da capital do estado do Piauí, Teresina. Sua população em 2009 era de 148.072 habitantes (IBGE) e o seu colégio eleitoral (2009) era de 98.929 eleitores (TSE). Constituindo-se, assim, no terceiro maior colégio eleitoral do estado, atrás somente dos municípios de São Luís e Imperatriz, primeiro e segundo maior colégio eleitoral do Maranhão, respectivamente. Nas campanhas municipais em 2008 em Caxias a disputa se caracterizou, basicamente, por coalizões rivais lideradas por duas "famílias de políticos, os "Marinho" e os "Coutinho". Destacamos duas mulheres nessa disputa: uma "Marinho"- candidata a prefeita- e uma "Coutinho" candidata a vereadora.

\section{MÁRCIA MARINHO “CAXIAS NO CORAÇÃO”}

Márcia Marinho, neta de comerciantes, filha de mecânico e de uma desembargadora. Foi candidata pelo PMDB à Prefeitura no município de Caxias (MA) do ano de 2008. Teve sua primeira incursão política aos 31 anos, em 1994, assumindo como deputada federal, filiada ao PSC (mesmo partido do marido). Formada em Medicina pela Universidade Federal do Maranhão, foi Secretária Municipal da Criança e Ação Social em 1993 em Caxias (MA), período em que seu esposo, Paulo Marinho, era prefeito do referido município.

Em 1996, Márcia Marinho muda de partido indo para o PSDB. Disputou as eleições de 2000, sendo eleita prefeita de Caxias (MA) pelo PFL (atual DEM, partido que até pouco tempo pertencia a atual governadora do Maranhão, Roseana Sarney). Em 2002, seu esposo reelege-se pela terceira vez deputado federal. Foi Gerente Regional do município de Pedreiras (MA), em 2000, à época do governo de Roseana Sarney. O "casal" Paulo Marinho e Márcia Marinho demonstraram em diferentes campanhas vinculações com a "família Sarney”.

Observamos aqui, por meio das movimentações entre Márcia Marinho e seu marido, tanto na prefeitura de Caxias (MA) como no cargo de deputado federal, a interdependência entre os princípios que regem as lutas políticas locais, estaduais e nacionais. Possibilitando Márcia Marinho ser uma das poucas mulheres maranhenses a 
ocupar o cargo de deputada federal ${ }^{6}$.

Nas campanhas municipais de 2008, tivemos a oportunidade de acompanhar um comício, uma passeata e entrevistar a candidata Márcia Marinho (PMDB). Esta ao ser questionada sobre o início de sua participação na política relembra dois fatos, que na sua explicação, podem ter sido marcantes. Primeiro destaca que na sua infância seu avô foi vereador em Caxias (MA), em segundo lugar, menciona que na sua trajetória escolar sempre participou ativamente como liderança de turma. Mas aponta como determinante a participação na campanha de seu esposo em 1990 para deputado federal, na qual ele foi eleito, sem passagem por deputação estadual ou vereança anterior.

Márcia Marinho disputou as eleições de 2008 pelo PMDB, em coligação (denominada “A Melhor para Caxias") com o DEM (partido pelo qual Roseana Sarney concorreu ao governo do estado em 2006), PP, PV (partido que tem como principal "liderança" estadual Sarney Filho, irmão de Roseana Sarney), PTB (partido ao qual são filiados importantes aliados da "família Sarney", como Manoel Ribeiro e Pedro Fernandes), PR e PRTB.

A candidata teve como slogan "Caxias no Coração" (que tem forte ligação com o fato de ser médica pediatra e ser caracterizada como "mãe"). Nesse sentido, uma locução do programa de Márcia Marinho é ilustrativa dessa aproximação entre a medicina, a "sensibilidade" e a "qualidade" de gestora pública:

\begin{abstract}
Uma médica para cuidar das pessoas. Uma especialista em gestão pública, para cuidar bem dos recursos que são do povo. Uma mulher com sensibilidade, para entender o que a sua gente mais precisa. Uma prefeita para tocar Caxias com competência, experiência, com força política. Para um povo ser feliz, existem muitos caminhos, e para o que Caxias precisa, existe Márcia prefeita (Programa de Márcia Marinho no HGPE).
\end{abstract}

Algo mais pode ser dito acerca da locução. Atributos como "competência" e "experiência” são conjugados no sentido de dar suporte a uma "boa gestão”, em contraponto às "denúncias" de corrupção que são constantemente veiculadas pelos programas de Márcia Marinho em direção a seu principal adversário na campanha, Humberto Coutinho. A "força política" faz menção ao conjunto de acessos e apoios que a candidata dispõe.

Em programa de Márcia Marinho, uma senhora, aposentada, bastante comovida, diz a respeito da candidata:

\footnotetext{
${ }^{6}$ Em um espaço de 24 anos (de 1982 a 2006) apenas 4 mulheres foram eleitas deputada federal no Maranhão: Roseana Sarney, Márcia Marinho, Nice Lobão e Terezinha Fernandes. Para maiores detalhes ver COSTA (2009).
} 
Eu espero tanto que a Márcia ganhe pra ela fazer a benfeitoria da nossa cidade, que tá acabada. Eu amo a Márcia. Eu tenho minhas criança que foi na creche botado por ela. E eu amo ela demais, e eu peço a Deus que ela vai ganhar, em nome de Jesus (Depoimento no HGPE)

Não são raras, nos programas de Márcia Marinho no HGPE, referências como “é Deus no céu e Márcia Marinho na terra" e similares. Podemos perceber que este caráter "humanizado" tem uma forma de pessoalização (na medida em que considera características que seriam inerentes aos candidatos e que os distinguem dos demais) e mesmo de sacralização.

Na campanha, o fato de ser médica pediatra é mobilizado para denotar um contato maior com as crianças, aparecendo em seu programa, com freqüência, imagens da candidata sendo abraçada por muitas delas. Concomitante a isso, elementos como "amor" e "afeto" são constantemente difundidos em sua campanha:

\author{
"Eu voto na decência/ \\ No sorriso aberto/ \\ Trabalho e no amor/ \\ No carinho e no afeto" \\ (Jingle de Márcia Marinho)
}

Numa referência ao status atribuído a Caxias de "Cidade das Letras", por ter uma série de poetas e intelectuais reconhecidos oriundos dela, exclama-se no programa de Márcia Marinho: "Reage Caxias! Numa terra de tantas letras, político tem que ter palavra!”. A menção a isso também se observa em um pronunciamento de Márcia Marinho, em "grande comício" realizado juntamente com Roseana Sarney, e que foi colocado em seu programa:

Esta cidade vai voltar a ter o respeito de quem é de respeito. Em honra à memória de Gonçalves Dias, Vespasiano Ramos, Coelho Neto e de tantos outros conterrâneos ilustres, que com certeza se envergonhariam das práticas que aqui se vêem hoje.(Pronunciamento de Márcia Marinho em comício, veiculado em um de seus programas no HGPE).

A questão de gênero é acionada por Márcia Marinho, ao ser tratada, em inserção nos comerciais, do fato de um vereador (da facção de Humberto Coutinho e registrado como um dos seus "homens de ouro") ter agredido fisicamente uma professora em frente à Câmara Municipal de Caxias, em 2005, ao passo em que se exibem imagens da agressão, que foi filmada. Assim, busca registrar a "impunidade" do referido vereador e, além disso, enaltecer o gênero, com exclamações do tipo: "Reage Mulher!" e "Márcia, 15! É mulher, é de luta!”. 


\section{THAYS COUTINHO - DE "SOBRINHA DE PREFEITO" À HERDEIRA POLÍTICA}

O membro da "família Coutinho" que ingressou mais recentemente na arena política é Thaís Garcia Coutinho Guimarães, sobrinha de Humberto Coutinho (atual prefeito). Ela é filha de Ferdinando Coutinho (irmão de Humberto Coutinho, vereador pelo município de Caxias (MA) em quatro legislaturas e atual vereador e presidente da Câmara de Vereadores do município de Matões, como já explicitado) e de Maria Gorete, que exerce a profissão de esteticista na capital do estado, São Luís. Tem 31 anos. Formada em enfermagem pela Universidade Federal do Maranhão - UFMA (2003), em São Luís. Teve uma escolarização que é pautada por passagens, segundo ela, pelos "melhores colégios", tendo estudado em Caxias (MA) e em Fortaleza, antes de ir para São Luís. "Eu sempre gozei de boa formação” (Entrevista com Thaís Coutinho).

É casada com um empresário do ramo de construção, que possui o curso de engenharia inconcluso. Nas palavras de Thaís Coutinho: "Ele [o marido] é empresário, porque no último ano [da faculdade], foi o ano que o pai dele morreu. Ele largou a faculdade pra trabalhar com as coisas do pai dele" (Entrevista com Thaís Coutinho). Sua madrasta, Cláudia Fabiana Ferreira Silva, se candidatou à vereadora em 2004, ficando na suplência e, posteriormente, assumindo o mandato no decorrer da legislatura 2005-2008.

Foi vereadora de Matões (MA) na legislatura 2001-2004 (seu pai, como exposto acima, era vereador em Caxias (MA) neste período), elegendo-se com 21 anos, concomitante aos estudos universitários. Aos 22 anos, se afastou do mandato para assumir como Secretária de Obras deste município.

Em 2008, candidatou-se novamente a vereadora, mas agora em Caxias (MA). E foi eleita com a terceira maior votação. Thaís Coutinho não se candidatou a nenhum cargo eletivo em 2004. Nesse meio tempo, trabalhou como enfermeira nas cidades de Igarapé Grande (MA) e Pedreiras (MA), tendo se deslocado para esses municípios em função do marido. Atualmente em Caxias (MA), e concomitantemente ao mandato de vereadora, Thaís Coutinho é supervisora em hospital e trabalha na Secretaria de Saúde de Caxias. "Ajudou”, segundo suas palavras, nas campanhas a vereador de seu pai (não ocupou nenhuma coordenação de campanha) quando se encontrava no município. Já que durante algum tempo morou fora da cidade, em virtude dos estudos. É filiada há dez anos ao PDT, seu primeiro e único partido político, poucos anos antes da sua candidatura e eleição como vereadora em Matões.

Sobre as justificações para a sua candidatura a vereadora em Caxias (MA), 
Thaís Coutinho deixa transparecer um elemento importante para a reprodução do "grupo familiar" na arena eletiva. Diz ela que disputou o pleito por "indicação do pai”. Em suas palavras:

\begin{abstract}
As coisas acontecem comigo... É Deus que coloca. Eu nunca imaginei que ia voltar pra política. Pelo parentesco, a Cláudia [madrasta] não podia mais ser vereadora, aí eu surgi de novo, aí eu fui. Mas aí eu quis fazer de forma diferente, aí eu tô trabalhando, tô dando assistencialismo individual, mas coletivo... Hoje é diferente da época de Matões, até pela maturidade que eu tenho hoje, né? Mas não foi por que eu queria, por idealismo não. [Foi] porque ela não podia ser. (Entrevista com Thaís Coutinho)
\end{abstract}

A "herança" do "patrimônio político familiar" implica em uma série de obrigações e deveres que visam à reprodução da "família”. "É preciso se mostrar digno de seu nome" (SAINT-MARTIN, 1992). Isto fica explícito no trecho acima, quando Thaís Coutinho afirma não ter sido uma vontade explícita sua tornar a disputar uma eleição, sendo o seu pai (Ferdinando Coutinho, irmão de Humberto Coutinho) responsável pela sua candidatura.

O investimento inicial no "jogo político" é um processo de transformação de disposições originárias em disposições específicas concernentes ao espaço político. Um "herdeiro", geralmente, afirma uma precocidade de contato com os signos e linguagens da "política" (BOURDIEU, 1998; GRILL, 2008). Nesse sentido, o trecho seguinte é bem ilustrativo:

\footnotetext{
Eu sempre gostei de política. Eu sempre fui política, porque a política é a pessoa que trabalha com as pessoas, com o povo, né? De dar assistência... Eu sempre gostei. Meu pai tem a fazenda e tinha muita gente na fazenda morava de 150 famílias. E lá eu sempre tava perto das pessoas, eu sempre gostei, porque tem gente que não gosta de gente não, eu gosto. Então eu sempre tava perto das pessoas. (Entrevista com Thaís Coutinho)
}

Aqui, cabe um parêntese para algo que Palmeira (2006) observa, a saber, a dimensão do assistencialismo enquanto um importante elo que une o "político" e o "eleitor". Constitui-se num dos elementos fundamentais das relações patrão-cliente (LANDÉ, 1977a; GRYNSZPAN, 1990) e da articulação de cadeias de líderes seguidores (LANDÉ, 1977b), qual seja, a capacidade do patrão de realizar favores.

A precocidade do ingresso dessa "herdeira" no espaço de disputa política é sintomático, pois aponta, dentre outras coisas, para o acúmulo de um capital de relações sociais por parte da "família", que acarreta, por sua vez, num acúmulo de capital simbólico, que tornou as condições muito mais favoráveis ao seu ingresso na arena eletiva. 
Ao ser questionada acerca da possível "vantagem" que teria ao concorrer nas eleições de 2008 ao lado do seu tio (Humberto Coutinho), Thaís responde:

Ah, pelo respaldo de ser 'Coutinho', ele ser meu tio e trabalhou muito bem. Então as pessoas: "Poxa, ser o tio dela". Você vê também pela história familiar (a história familiar, política), é de honestidade, de respeito. $\mathrm{E}$ isso fez também que eu entrasse com respaldo bem maior do que outras pessoas que não tinham esse nome, né? O 'Coutinho'. Eu não tô fazendo feio também não. (Entrevista com Thaís Coutinho)

Transparece o fato de que o "nome" - ser um "Coutinho"- "projeta" Thaís Coutinho de uma maneira diferenciada no espaço político em relação aos demais candidatos envolvidos na disputa eleitoral. Apontando nesse sentido, Saint-Martin (1992), ao estudar os membros da "nobreza" francesa, identifica o "nome" como sendo um importante elemento de distinção. Juntamente com o título de nobre, o nome manifesta "aos olhos de todos o capital simbólico da família, evocam o passado da família (...) E, por outro lado, (...) eles empenham a honra da família”.

De maneira semelhante, Wolf (2003), orienta que os "nomes de família" devem ser analisados enquanto formas de "estocagem e aumento da virtude" da família (p.101). Bourdieu (1996) afirma que o nome é resultado de um rito de instituição inaugural que garante uma espécie de essência social do "nome", que o torna passível de transmissão "qualidades" inerentes ao nome através das "gerações". Assim, na tentativa de manter (e, por isso mesmo, reproduzir) estas "qualidades", como expõe Bourdieu (1996, p.78), os deveres mais sagrados com relação a si mesmo tomem a forma de deveres em relação ao nome próprio (que é sempre também, por um lado, um nome coletivo, como nome de família, especificado por um prenome).

Thaís Coutinho utiliza o parentesco e o trabalho do tio à frente da prefeitura e toma para si um "histórico familiar" que abarca valores morais ("honestidade" e "respeito") sedimentados enquanto valores "intrínsecos" dos "Coutinho", que, na sua apresentação, passam automaticamente a fazer parte do seu repertório pessoal. Assim, a construção se dá no sentido de um ajustamento entre o "legado familiar" (os diferentes recursos acumulados ao longo do tempo) e o seu itinerário pessoal. Desta forma, a justificação do "parentesco" ganha legitimidade (GRILL, 2008), na medida em que se constrói essa "pertença" ao "grupo familiar". Sobre isso, afirma Grill (2008, p.63):

A inscrição dos agentes em um 'família de políticos' contribui como fonte de crédito e de notoriedade, possibilitando que os mesmos sejam reconhecidos como portadores de 'qualidades', 'atributos', 'imagens', além de direitos que são reconhecidos pela origem familiar. 
Podemos observar como a estratégia de inscrição de Thaís Coutinho na "história familiar" é reconvertida em trunfo na disputa eleitoral de 2008, buscando a diferenciação em relação aos demais políticos.

\section{LAYANNA FERREIRA - NOVA GERAÇÃO E HERANÇA POLÍTICA EM PINHEIRO (MA)}

Pinheiro (MA) é um município maranhense de médio porte. Com cerca de 80 mil habitantes e 50 mil eleitores. Em relação à política, possui características que a aproximam da capital, São Luís. Como exemplo, citamos a contratação de profissionais específicos para certos cargos nas equipes de campanhas dos candidatos. Por outro lado, a pessoalidade é um forte traço da política local, o que coloca Pinheiro (MA) em consonância com um município de pequeno porte. A cidade é a maior da região onde está inserida, a Baixada Maranhense.

Layanna Ferreira é filha do locutor e comentarista de rádio e televisão, Tony Ferreira. Seu pai, devido à popularidade adquirida pelo programa - que visa atender problemas de pessoas humildes e denunciar os possíveis erros cometidos pela administração municipal e projetar políticos de sua facção-, teve a possibilidade de ser candidato ao cargo de vereador em 2004 em Pinheiro (MA). Naquela época estava filiado ao PSDB. Venceu as eleições, conseguindo 1.607 votos.

Em 2006, candidatou-se a deputado federal apoiado pelo então governador do estado do Maranhão, Jackson Lago. Teve como principal adversário político na região da Baixada Maranhense e, por conseqüência, do município de Pinheiro (MA), José Sarney Filho. No computo geral, obteve 22.141 sendo 14.981 na cidade de Pinheiro (MA).

Em comparação, Sarney Filho teve 7.205 votos. Tendo como norte o número total de eleitores votantes na cidade naquela eleição, 35.357, Tony Ferreira conseguiu 42\% dos votos e Sarney Filho 20\%. Tais números, porém, não foram suficientes para que Tony Ferreira conseguisse sua eleição, ficando como suplente.

Segundo informações colhidas em conversas com amigos de Tony Ferreira, seu objetivo nas eleições de 2006 era alavancar seu nome visando à disputa municipal de 2008 pelo PDT. Porém, a entrada no jogo político local de um candidato conhecido como Dr. Léo impediu a candidatura, uma vez que ambos eram filiados ao PDT e o partido escolheu o segundo.

Tony Ferreira tinha a possibilidade de ser candidato a vice ou a vereador, mas preferiu ausentar-se do pleito por dois motivos: primeiramente, sendo candidato a vice na chapa de Dr. Léo, estaria aceitando a subordinação a um "estrangeiro", como era 
tratado Dr. Léo; segundo, sendo candidato a vereador, teria muitos votos e elegeria alguns adversários políticos, mesmo que do mesmo partido. Assim, preferiu lançar sua filha, Layanna Ferreira como candidata a vereadora por um partido pequeno (Partido Humanista da Solidariedade). A estratégia deu certo. Layanna Ferreira foi a candidata mais votada no município no pleito de 2008, obtendo sua eleição com 2.478 votos. Dos quatro casos aqui analisados, ela foi a candidata mais nova a conseguir se eleger, com apenas 19 anos.

Ao analisarmos a trajetória de Layanna Ferreira, percebemos que esta viveu sua infância e adolescência em meios políticos. A iniciação de Layanna Ferreira no meio político, semelhante aos outros casos analisados, ocorreu precocemente. Diversos textos abordam a iniciação do político dentro do seio familiar e que seguir a "vocação política" nada tem de natural. Letícia Canêdo (1991) revela que a "vocação" é a "internalização de um sistema de categorias, de percepções, de pensamentos e de ações continuamente confirmados e legitimados pelas práticas levadas a bom termo pelos descendentes de antigas famílias de políticos" (p. 222). Nesse sentido, a trajetória de Layanna Ferreira lembra o que nos diz Canêdo (1991):

A criança desde cedo vê desfilar em casa os mais diversos visitantes, de políticos a solicitadores, denominados "protegidos" da família. Faz parte da sua vida particular dos acontecimentos sociais locais, nos quais percebe os olhares dos presentes sobre o seu grupo familiar. Cumprimentar convidados, parentes e amigos, aprender a sorrir, deixar brinquedos e freqüentar festas de casamentos na roça, escutar distraidamente conversações de políticos, acompanhar o trabalho entre os eleitores e a "elevação da temperatura" na vida familiar às vésperas das eleições, perceber os pequenos cuidados necessários para dominar os detalhes do jogo básico do homem político, tudo isso faz parte da conduta regular de uma criança e representa a forma de capital mais importante dentre todas as que constituem investimento para o sucesso na carreira política (CANÊDO, 1991, p. 232. Grifo nosso).

Em relação à campanha de 2008, Layanna Ferreira enfatiza a "traição" sofrida pelo pai em seus atos de campanha e material de propaganda. O santinho trazia a foto da candidata, seu número, o símbolo do partido (Partido Humanista da Solidariedade PHS) e o slogan, além da foto de seu principal apoiador, seu pai, Tony Ferreira, juntamente com uma frase sobre ele.

Esses dois últimos elementos explicam a inserção de Layanna Ferreira no pleito, haja vista que é uma resposta aos acontecimentos políticos no seio da "oposição" em Pinheiro (MA). A frase de ordem da candidata é "Contra a traição" e a oração sobre seu pai diz "Apoio: Tony Ferreira, vítima da maior traição política de Pinheiro". No verso ainda aprecem duas vezes a frase "contra a traição". 


\title{
MAURA JORGE - RUMO À PREFEITURA DE LAGO DA PEDRA (MA)
}

Maura Jorge (DEM) nasceu em Lago da Pedra (MA), no início dos anos 6o. É filha do fazendeiro Waldir Jorge e da ex-prefeita Raimundinha Jorge. No período da pesquisa estava no seu quarto mandato de deputada estadual. Sua família participa das disputas políticas em Lago da Pedra (MA) há muitos anos contra a facção política liderada por Luis Osmani (PDT). Em meio a esse período sua mãe chegou a exercer quatro mandatos como prefeita da cidade. Maura Jorge ao relatar sobre a origem política de sua família ressalta o fato de seu pai combater, na época, o chamado Vitorinismo em Lago da Pedra (MA):

\begin{abstract}
Naquela época, tinha o Vitorinismo muito forte aqui na nossa região e meu pai como sempre um jovem destemido, foi quem levantou a bandeira de oposição, porque tinha só uma ala preponderante, que mandava na época, não me lembro muito bem o motivo, boicotaram a candidatura dele, e ele achou por bem enfrentar e lançou para a candidatura minha mãe, a origem da nossa política foi o meu pai, mas por conta disso. (Maura Jorge entrevista concedida em 20/07/08)
\end{abstract}

O fato de ter uma mãe prefeita marcou a infância de Maura Jorge, que desde criança, já a acompanhava nas inaugurações das obras, nos discursos, e sempre gostava de observar o trabalho social. Raimundinha Jorge teve seis filhos, quatro mulheres e dois homens, dentre os quais, Maura Jorge e o caçula- Waldir Filho - desde cedo gostavam de participar das atividades políticas da mãe. Maura Jorge afirma que antes da sua mãe ser prefeita, a cidade de Lago da Pedra (MA) não tinha praticamente nenhuma estrutura. Para ela, o primeiro mandato de sua mãe marca a origem de Lago da Pedra (MA). O desenvolvimento de trabalhos sociais fazia parte do cotidiano de Maura Jorge e de seu irmão mais novo, o que acabou contribuindo para que ambos futuramente disputassem cargos eletivos, ela lembra:

[...] eu comecei a me envolver com o trabalho social, com associações. Ele era o mais novo e eu a mais velha. Tínhamos assim uma identidade eu e ele. E nós começamos assim a fazer esses trabalhos sociais, com associações. Eu tinha 20 anos e foi a partir desses trabalhos, que surgiu a ideia de candidatura dele pra prefeito. Foi o prefeito mais novo do Brasil, acho que com 22 anos e era um ídolo pra mim, apesar de eu ser mais velha. (Maura Jorge - entrevista concedida em 20/07/08, grifos nossos).

Maura Jorge nutre até hoje um sentimento de "adoração" pelo irmão, disse que ele foi um grande exemplo para ela, que tenta fazer política inspirada no jeito que 
ele fazia. O irmão mais novo de Maura Jorge, Waldir Filho, foi eleito prefeito de Lago da Pedra (MA) em 1988, período em que foi presidente da Federação dos Municípios do Estado do Maranhão - FAMEM, por dois mandatos. Em 1994, foi eleito deputado estadual, mas não chegou a exercer até o final do mandato devido um acidente aéreo em 1995, do qual foi vítima fatal durante viagem para participar de uma itinerância da Assembléia Legislativa. Apesar da morte ter ocorrido há mais de dez anos, no trabalho de campo, foi possível perceber que esse sentimento de grande admiração por Waldir Filho, não é mantido apenas por Maura Jorge, mas por várias pessoas do município.

Maura Jorge com 29 anos foi eleita deputada estadual pela primeira vez em 1990. Aqui percebemos como os demais casos apresentados, o recrutamento precoce que muitas vezes ocorre entre os profissionais políticos, e o tempo de dedicação exigido para aqueles que querem se dedicar à carreira política (OFFERLÉ, 1999). Maura Jorge não chega sequer a exercer a profissão de advogada, por ter escolhido se dedicar à carreira política, afirmando que não conseguiu conciliar as duas coisas.

Outro elemento é a "influência da família”, mencionada por Maura Jorge, que apesar de ela se referir ao momento específico de indicação da candidatura, percebe-se em outros momentos da construção de sua trajetória, que, muito antes da candidatura houve um trabalho de socialização e incorporação de práticas concernentes à política devido ao ambiente em que Maura Jorge cresceu, habilidades adquiridas nos trabalhos sociais com o irmão, relações de parentesco com políticos e vínculos da família Jorge com outras famílias de tradição política do Maranhão.

No caso em pauta, o nome de registro da candidata é Maura Alves de Melo Ribeiro, mas devido ao reconhecimento do nome de seu pai- Waldir Jorge- como o fundador do "grupo político" e da associação feita por muitos moradores de Lago da Pedra (MA) do nome "Jorge" com os principais feitos e obras realizados nesse município, ela adotou o nome parlamentar Maura Jorge.

$\mathrm{Na}$ campanha de 2008, no trabalho de campo, ouvimos algumas vinhetas e propagandas que passavam na rádio Santa Maura, divulgando a campanha, este também foi reproduzido como fundo de um telão que passavam imagens da candidata na abertura de um comício. Destacamos um trecho abaixo onde o pertencimento à região combinado a "tradição política familiar" é o que inicia a chamada:

Natural de Lago da Pedra, filha de Waldir Jorge de Melo e Raimunda Alves de Melo, Maura Jorge iniciou a vida política no município de Lago da Pedra onde sua família tem tradição política e social na história do município, sua mãe foi prefeita por quatro mandatos com uma grande folha de serviços prestados ao povo de sua terra, seu irmão Waldir Jorge de Melo Filho foi prefeito de Lago da Pedra e exercia o mandato de deputado estadual quando faleceu vítima de 
acidente aéreo, Maura Jorge está no seu quarto mandato de deputada estadual e agora encara mais esse desafio disputar as eleições municipais aqui em Lago da Pedra (...) e é por isso que o povo de Lago da Pedra quer Maura Jorge como prefeita dessa cidade para dar continuidade ao seu trabalho na construção de uma Lago da Pedra melhor (trecho do material de campanha divulgado na rádio Santa Maura, grifos nossos)

O uso estratégico do fato ter nascido no município de Lago da Pedra (MA) pode ser identificado nos depoimentos, como trunfo acionado pela candidata. Ser lagopedrense foi um dos códigos acionados por Maura Jorge nas campanhas municipais. Maura Jorge afirma ter aprendido muito sobre política nos quatro anos do primeiro mandato. Esta consegue não só as reeleições, como aumenta consideravelmente sua margem de votação. Nas três eleições pelo antigo PFL ela obteve sucesso nas urnas. Segundo dados do TRE, ela se elegeu em 1990 deputada estadual com 14.219 votos. No ano de 1998 aumentou para 27.253 votos. Em 2002 sobe para 37.612 votos e nas últimas eleições, no ano de 2006 concorreu pelo PDT perdendo alguns números de votos. Mas ainda assim foi uma das deputadas mais votadas com 34.126 votos. Como a facção política de Maura Jorge perdeu as eleições municipais em Lago da Pedra (MA) em 2004. Em reuniões, a indicaram como "salvadora da pátria", como ela costuma falar. A percepção da sua facção política é de que o nome Maura Jorge, era o único que poderia vislumbrar essa chance de retomar o poder municipal em Lago da Pedra (MA).

Nas disputas políticas em 2008, Maura Jorge se autoconsagra "a mulher certa” para administrar Lago da Pedra (MA), anunciada em seu jingle de campanha. Não apenas pelos aspectos anunciados na letra: "aquela que tem alegria", "que está com o povo todo dia", "a candidata da massa”, mas baseada também em símbolos do sagrado7, como a bíblia e designações associadas a esse universo: "aquela que anda na verdade", "escolhida por Deus", "agente da esperança”.

Assim, por meio da análise das diferentes situações, notamos que a campanha de Maura Jorge, em 2008, foi realizada enfatizando-se principalmente alguns elementos: a tradição política da "família Jorge", a identidade regional, a atuação enquanto deputada estadual, a dimensão do sagrado e o gênero. Ela foi eleita prefeita de Lago da Pedra (MA) com 12.659 votos, enquanto a candidata da outra facçãoFátima Sales- obteve 12.097 votos. Demonstrando o clima ainda de competição entre as facções.

Com seu prestígio reforçado, Maura Jorge, que é evangélica, depois de eleita encontrava-se diante do desafio de comemorar com seu eleitorado evangélico sem

\footnotetext{
7 A análise de Barreira (1998:66) destaca: "Não por acaso, os rituais da política têm tradicionalmente evocado, de modo direto ou indireto, a presença do sagrado, a partir de símbolos deslocados e readaptados a cada situação particular”.
} 
desagradar aos demais. A candidata juntamente com sua equipe de campanha, decidiu comemorar o êxito obtido nas urnas, fazendo duas noites de festa em Lago da Pedra (MA): um culto no dia onze e um forró no dia doze de outubro de 2008.

\section{CONSIDERAÇÕES FINAIS}

Nossa intenção ao longo desse trabalho foi analisar o processo de profissionalização política no Maranhão sob um recorte de gênero. Essa iniciativa se desdobrou em dois sentidos: identificar os perfis e trajetórias de candidaturas de mulheres maranhenses nas eleições municipais de 2008 e refletir sobre as estratégias de reconversão de bases sociais em trunfos eleitorais.

Como parte da demonstração das possibilidades de combinação e acionamento de trunfos políticos ao longo dos itinerários das mulheres em campanha. Analisamos quatro casos mais detalhadamente: o percurso de duas candidatas a prefeita e duas a vereadora. Em todos os casos, o círculo familiar contribuiu para internalização das práticas políticas e as relações de parentesco foram acionadas pelo reconhecimento nas urnas, com destaque para Layanna Ferreira, cujo santinho trazia sua foto junto com seu pai.

Os dados evidenciaram também, que todas ingressaram cedo no primeiro cargo eletivo, Layanna Ferreira sendo eleita vereadora com 19 anos. Thays Coutinho foi vereadora com 21 anos. Maura Jorge, deputada estadual aos 29 anos e Márcia Marinho, deputada federal aos 31 anos. As duas que iniciaram suas carreiras mais jovens começaram "por baixo", ocupando cargo de vereança. Na época da pesquisa, suas famílias eram oposição à "família Sarney". As duas que foram eleitas com mais de 25 anos ingressaram "por cima". Uma começa logo como deputada estadual e outra como deputada federal. Estas são da família "Jorge" e "Marinho", que em diferentes momentos declararam apoio a "família Sarney".

Corroborando as idéias de autores que discutem sobre o processo de profissionalização política, o tempo de dedicação dessas mulheres às atividades políticas, em geral, somam vários anos. Não apenas pelo número de mandatos acumulados, mas também por atividades desempenhadas antes da ocupação do cargo eletivo. Identificamos casos de passagem por secretarias, participação nas campanhas dos maridos ou do pai, antes de serem eleitas. O conhecimento e as práticas adquiridas nessas esferas acabam funcionando como capital significativo de diferenciação entre os concorrentes na arena política. 
Em relação ao uso do gênero como mecanismo para obtenção de legitimidade política, observamos que o acionamento ocorre, mas geralmente com menor peso em relação a outros trunfos eleitorais.

\section{REFERENCIAS BIBLIOGRAFICAS}

ACHIN,C. Le mystère de la chambre basse. Comparaison des processus d'entrée de femmes au parlement, France-Allemagne, 1945-20oo. Dalloz, Coll. Bibliotlèque dès Tlèses, 2005.

ARAGÃO, Elthon Ranyere Oliveira. Raposas, Herdeiros e Outsiders: especialização política e dinâmica eleitoral em Pinheiro - MA. Dissertação (Mestrado) - Universidade Federal do Maranhão, Centro de Ciências Humanas, 2010.

AVELAR, Lúcia. Mulheres na elite política brasileira. São Paulo: Fundação Konrad Adenauer, Editora da UNESP, 2001.

BARREIRA, I. Chuva de papéis: ritos e símbolos de campanhas eleitorais no Brasil. Rio de Janeiro: Relume Dumará, Núcleo de Antropologia Política, 1998.

Práticas parlamentares, habitus e performances no campo da política: a participação de mulheres no Congresso Nacional. In: 30 ${ }^{\circ}$ Encontro Anual da ANPOCS, 2006, Caxambu. $30^{\circ}$ Encontro Anual da ANPOCS. São Paulo : ANPOCS, 2006.

Imagens ritualizadas: apresentação de mulheres em cenários eleitorais. Fortaleza, CE: UFC/Funcap/CNPq-Pronex; Campinas, SP: Pontes Editores, 2008.

BOURDIEU, P. O Poder Simbólico. Rio de Janeiro: Bertrand Brasil, 1998

A ilusão biográfica. In: FERREIRA, M e AMADO, J. (orgs.) Usos e abusos da História Oral. Rio de Janeiro: FGV Ed, 1996a.

O espírito de família. In: Razões práticas: sobre a teoria da ação,

Campinas: Papirus, 1996b.

Stratégies de reproduction et modes de domination. Actes de la recherche en sciences sociales. Volume 105, $\mathrm{N}^{\circ}$ 1., p. $3-12,1994$.

CANÊDO, Letícia. Estratégias familiares na produção social de uma qualificação política. In: Educação e Sociedade. Nº 39, Ano XII, 1991.

COSTA, Dayana dos S. D. Mulheres e Especialização Política: trajetórias e recursos eleitorais entre as deputadas federais/estaduais do Maranhão. Dissertação (Mestrado) - Universidade Federal do Maranhão, Centro de Ciências Humanas, 2009.

DULONG, Delphine. SANDRINE, Lévêque. Une ressource contigente. Les conditions de reconversion du genre em ressource politique. Politix, v.15, $\mathrm{n}^{\circ} 60$, 2002. P. 81-111.

GRILL, I. G. As bases sociais do compromisso: a constituição de um espaço de concorrência eleitoral no sul do Rio Grande do Sul. Dissertação de mestrado, UFRGSIFCH-PPG Ciência Política, 1999. 
Processos, condicionantes e bases sociais da especialização política no Rio Grande do Sul e no Maranhão. In: 31. ${ }^{\circ}$ Encontro Anual da Anpocs, 2007, Caxambú. 31. ${ }^{\circ}$ Encontro Anual da Anpocs, 2007.

. Diversificação Social da 'Elite Política', 'heranças' e usos do parentesco no Rio Grande do Sul. In: GRILL, Igor G. "Heranças políticas" no Rio Grande do Sul. São Luís: EDUFMA, 2008.

GUIONNET, Christine. Entrées de femmes em politique. L'irréductibilité du genre à l'heure de La parité. Politix, v.15, nº6o, 2002. P.113-146.

GRYNSPAN, Mário. Os Idiomas da patronagem: um estudo da trajetória de Tenório Cavalcanti. Revista Brasileira de Ciências Sociais, n.14, outubro de 1990.p.1-10.

KUSCHNIR, K. O Cotidiano da Política. Rio de Janeiro: Zahar, 2000.

. Antropologia da Política. Rio de Janeiro: Jorge Zahar, 2007.

LAGROYE, J. Être du métier. Politix, Année 1994, Volume 7, Numéro 28. p. 5 - 15.

LANDÉ, Carl H. Introduction: the dyadic basis of clientelism. In: SCHMIDT, S.W.; alli.(Orgs.). Friends, followers and factions. A Reader in political clientelism. Berkeley: University of California Press, 1977a.

. Groups politics and dyadic politics: notes for a theory. SCHMIDT, S.W. et alli.(Eds.). Friends, Followers and Factions. A Reader in political clientelism. Berkeley, University of California Press, 1977b. (em português).

LIMA, João Gilberto do Nascimento. Bases Sociais, Facções e Mediação: o processo de seleção de "elites locais" e a dinâmica de concorrência eleitoral em um município maranhense. Monografia de Conclusão do Bacharelado em Ciências Sociais - Universidade Federal do Maranhão, Centro de Ciências Humanas, 2009.

MAYER, Adrian C. A importância dos quase-grupos no estudo das sociedades complexas. In: FELDMAN-BIANCO, Bela (org.). Antropologia das sociedades contemporâneas. São Paulo: Global, 1987.p.127-155.

MIGUEL, Luís Filipe. Política de interesses, política do desvelo: representação e singularidade feminina. Rev. Estudos Feministas, ano 9, $2^{\circ} \mathrm{sem} .2001$.

OFFERLÉ, Michel. Entrées en politique. Politix, V. 9, No³5, p. 3 - 5, 1996

OFFERLÉ, M. Professions et profession politique. In: La Profession politique. Paris: Belin, 1999.

PALMEIRA, M. Eleição municipal, política e cidadania. In: PALMEIRA, M. G.S;

Barreira, C. Política no Brasil: Visões de antropólogos. Rio de Janeiro: Relume-

Dumará, 2006.

SAINT-MARTIN, Monique de. A nobreza em França: a tradição como crença. In: Revista Brasileira de Ciências Sociais, ${ }^{0}{ }_{20}$, 1992.

SCOTT, J. Uma categoria útil de análise histórica. In: Educação e Realidade: mulher e educação, v.15. 1990.

WEBER, Max. Ciência e Política: duas vocações. São Paulo: Ed. Martin Claret, 2002. 
WOLF, Eric. Aspectos das relações de grupos em uma sociedade complexa: México. In: WOLF, Eric. Antropologia e poder: contribuições de Eric R. Wolf. RIBEIRO, Gustavo Lins, BIANCO, Bela Feldman (Orgs.). Brasília: Ed. UnB; São Paulo:Imprensa Oficial; Campinas: Ed. Unicamp, 2003.

\section{Entrevistas realizadas:}

Márcia Marinho. Realizada no município de Caxias (MA), em 15/o9/o8

Maura Jorge. Realizada no município de Lago da Pedra (MA), em 20/07/o8

Thaís Coutinho. Realizada no município de Caxias (MA), em 13/08/o9 